\title{
O uso do Facebook pelas Bibliotecas Públicas do estado do Ceará
}

\author{
The use of Facebook by the Public Libraries in Ceara
}

\author{
Maria Cleide Rodrigues Bernardino \\ Doutora em Ciência da Informação pela Universidade de Brasília - UnB. \\ Professora Adjunta do Curso de Biblioteconomia da Universidade Federal do Cariri. \\ E-mail: cleide@cariri.ufc.br
}

Emir José Suaiden

Doutor em Ciência da Informação pela Unversidade Complutense de Madrid. Professor Titular da Faculdade de Ciência da Informação - UnB. Bolsista produtividade em pesquisa CNPq. E-mail: $\underline{\text { emir@unb.br }}$

Aurora Cuevas-Cerveró

Pós-Doutora pela Universidade de Brasília - UnB.

Professora Pesquisadora da Universidad Complutense de Madrid - UCM.

E-mail: auro.cuevas@gmail.com

\section{Resumo}

O presente artigo traz uma análise sobre o uso do Facebook como canal de comunicação pelas bibliotecas públicas do Estado do Ceará. Trata-se de um estudo exploratório com o auxílio dos métodos funcionalista e fenomenológico e abordagem de caráter quantitativo. O objetivo é analisar o uso do Facebook pelas 184 bibliotecas públicas do SEBP/CE. Por fim conclui-se que o uso da internet e das redes sociais pelas bibliotecas públicas contribui para uma maior socialização e interação entre os usuários e para dar maior visibilidade a biblioteca pública e conseqüentemente divulgar seus serviços e atividades.

Palavras-Chave: Bibliotecas Públicas. Canal de Informação. Internet. Facebook.

\begin{abstract}
This paper presents an analysis of the use of Facebook as a communication channel by public libraries in the state of Ceará. This is an exploratory study with the aid of functionalist and phenomenological methods and a quantitative character approach. The aim is to analyze the use of Facebook by 184 SEBP / CE public libraries. Finally it is concluded that the use of the Internet and social networks by public libraries contribute to greater socialization and interaction between users and to give greater visibility to the public library and consequently promote their services and activities.
\end{abstract}

Keywords: Public Libraries. Channel information. Internet. Facebook. 


\section{Introdução}

A informação e os canais onde circulam sofreram transformações nos últimos anos. É fato que, a ênfase dada à informação e a rapidez com que é veiculada é um dos pontos altos da chamada sociedade da informação. Neste sentido, as tecnologias cada vez mais modernas que surgem quase que diariamente, contribuem de forma ímpar para a quebra de paradigmas sociais quanto ao fluxo da informação.

Podemos afirmar com base em Regis e Campos (2009, p. 2890) que essa tecnologia que é amplamente abordada e utilizada "compreende os meios com os quais, o homem amplia suas capacidades. Inclui não apenas instrumentos, máquinas e outros implementos, mas também os conhecimentos e as habilidades necessárias a utilização dos meios disponíveis". Isto significa que, a utilização de canais informais de comunicação científica está cada vez mais se tornando um meio de ampliar e maximizar o alcance da informação nesta sociedade contemporânea.

Dessa forma não devemos ignorar a importância dos canais informais de informação para a comunicação científica e dentre esses canais as redes sociais, mais especificamente o Facebook como um veículo de circulação e divulgação de informação científica cada vez mais utilizado na atualidade. Assim, este trabalho pretende identificar o uso dessa ferramenta pelas bibliotecas públicas que fazem parte do Sistema Estadual de Bibliotecas Públicas (SEBP) a fim de traçar um perfil do fluxo informacional científico, a partir da veiculação de informações na rede social Facebook.

Trata-se de uma pesquisa exploratória e descritiva de caráter quantitativo que permitirá conhecer e mapear as principais bibliotecas públicas cearenses a utilizarem o Facebook como canal informal para circulação de informações científicas. Pretende-se, portanto, contribuir para as discussões sobre a temática e possibilitar debates e indagações no campo científico, uma vez em que dialogando com Lenzi e Brambila (2006) afirmamos que a ciência nasceu a partir das indagações do homem sobre o mundo que vivia, possibilitando transformações e influenciando o mundo e o conhecimento. 


\section{Revolução Científica}

Conforme Lenzi e Brambila (2006, p. 2) o conhecimento cientifico moderno nasceu da "necessidade de explicação sobre os fatos contextuais, antes e até então conhecidos e transmitidos sob a influência do senso comum" e passou por diversas etapas ao longo da história. Essas etapas ou revoluções como pontua Drucker (1998), sendo que a primeira foi a invenção da escrita ocorrida na Mesopotâmia há aproximadamente 6 mil anos; a segunda foi a invenção do livro, que ocorreu na China em 1300 a.C., e mais tarde, cerca de 800 anos depois, na Grécia; e a terceira revolução é creditada por Drucker (1998) à invenção da imprensa por volta de 1400, por Gutenberg. Para Peter Drucker (1998) a quarta revolução da informação é de conceitos que busca responder ao questionamento sobre o significado e o propósito da informação. Entretanto, é inegável que esses conceitos sofreram por sua vez inúmeras transformações permeadas pelas inovações tecnológicas, que permitiram maior alcance, rapidez e acesso.

Foi no final do século XIX que, sob a forte influência da conjunção das ciências e da tecnologia, o mundo inicia um período de transição dos usos e costumes na produção e fluxo da informação. A internet passa a ser mais constante e presente na vida do homem que, consequentemente procura informação cada vez mais rápida. O surgimento da internet veio interferir profundamente no comportamento da sociedade, que se rende frente às inovações tecnológicas e suas complexidades, alterando sobremaneira, as relações de uso e circulação da informação.

Os avanços científicos e tecnológicos trouxeram significativas mudanças no processo produtivo e na obtenção de conhecimento que foram palco nas revoluções industrial, tecnológica e científica (BRANDÃO; DUQUE, 2011). Foi este processo evolutivo e gradativo que propiciou ao que se chama hoje de revolução tecnológica ou revolução da informação proporcionada pela tecnologia da informação e da comunicação. Santos (2004) observa que a partir do final do século XX se começou a viver um novo paradigma tecnológico, salienta ainda que este é o paradigma da revolução das tecnologias de informação e comunicação.

Estas transformações por sua vez modificaram também a forma de produção e uso da informação. Fatores como rapidez, acesso e fluidez são requisitos cada vez mais frequentes 
nesta nova Era em que se vive conectado a tudo que acontece no mundo. Esse processo evolutivo é corroborado por Castells (1999, p. 51) quando afirma que,

O que caracteriza a atual revolução tecnológica não é a centralidade de conhecimentos e informação, mas a aplicação desses conhecimentos e dessa informação para a geração de conhecimentos e de dispositivos de processamento/comunicação da informação, em um ciclo de realimentação cumulativo entre as inovações e seu uso.

O ciclo cumulativo de realimentação entre as inovações e o seu uso, significa mudanças no processamento dessa informação e no seu uso. As inovações tecnológicas proporcionam várias alternativas de interação e acesso à informação. Tanto a partir de canais formais de informação, que são resultado da atividade científica na sua forma tangenciada (OLIVEIRA, 1989), artigos de periódicos científicos, livros, trabalhos publicados em anais de eventos e outros; como dos canais informais, que segundo Oliveira (1989) não geram registros sistemáticos e não são controlados, o que implica em estudos complexos e que exigem do pesquisador metodologias específicas e detalhadas.

A comunicação informal compreende e-mails, pré-prints, colégio invisível, relatórios técnicos, palestras, conversas, dentre outros e se caracterizam pela comunicação de caráter pessoal. Eles podem gerar algum registro, porém em pequena tiragem.

\section{As Redes sociais como canal de comunicação}

As redes sociais estão extremamente popularizadas nos canais de comunicação tanto formais como informais, - se observarmos o uso do Facebook por empresas e organizações diversas -, a rede social é um meio de obter informação rápida, atualizada e de maior alcance. A facilidade com que se obtém a informação, algumas vezes remete à dúvida sobre sua autenticidade, comum em informações na rede. Outro fator importante é a efemeridade das informações veiculadas.

Para compreender a complexidade do conceito de rede social Marteleto (2007, p. 13) afirma que sua noção "designa em geral um conjunto de métodos, conceitos, teorias e modelos das ciências sociais, com diferentes matizes disciplinares e epistemológicos, que conservam princípios comuns entre eles".

Araújo (1979) destaca que o esforço de alguns pesquisadores em, 
[...] despertar atenção para o papel desempenhado pelos canais informais, vem trazendo resultados bastante positivos para o setor da ICT, quer no que diz respeito ao conhecimento de seus mecanismos e, consequentemente, a uma melhor utilização dos mesmos, quer no que diz respeito ao aspecto econômico do processamento da informação, o qual é, ainda, um dos fatores limitantes a sua ampla utilização, principalmente em países periféricos, carentes de recursos.

Notemos que esta observação foi antes da evolução das tecnologias de informação e comunicação e das redes sociais em nossa sociedade. Entretanto, nos parece deveras atualizada. O impacto das mudanças na área da tecnologia da informação é amplamente reconhecido pela comunidade científica e tem ênfase, sobretudo, no crescimento econômico e político da sociedade. Porém, estas inovações também repercutem no que diz respeito ao crescimento do conhecimento científico, sua circulação, disseminação e recuperação a partir dos canais de informação adequados.

Não podemos negar o alcance do Facebook na circulação da informação entre os usuários de qualquer idade, classe social, cultura etc. Ao reconhecer a penetrabilidade do Facebook como canal de comunicação, as bibliotecas universitárias estão também, reconhecendo que deve adequar-se aos costumes vigentes no que diz respeito ao uso e o fluxo da informação. Santos e Carvalho (2009, p. 52) afirmam que o "uso da informação deve ser visto como algo capaz de alterar de modo significativo à vida de um cidadão, já que a partir dela podem se gerar novas informações”.

\section{As Bibliotecas públicas em tempos de Facebook}

Cada vez mais as bibliotecas públicas estão utilizando as redes sociais para divulgação e marketing de seus serviços e atividades. Para Pontes e Santos (2011) as organizações e instituições de informação se utilizam das redes sociais na internet na busca de um melhor desempenho.

Em fevereiro de 2013, na reunião anual da American Association for the Advancement of Science (AAAS) ${ }^{1}$, ocorrida em Boston, EUA, o uso das mídias sociais foi defendido pelos participantes de um painel sobre comunicação em ciência. De acordo com o relatório The State os American Libraries $2012^{2}$, elaborado pela American Library Association (ALA), as

\footnotetext{
${ }^{1}$ Disponível em: http://www.aaas.org/meetings/2013/

${ }^{2}$ Disponível em: http://www.ala.org/news/sites/ala.org.news/files/content/StateofAmericasLibrariesReport2012Finalwithcover.pd $\underline{\mathrm{f}}$
}

InCID: R. Ci. Inf. e Doc., Ribeirão Preto, v. 5, n. 1, p. 112-123, mar./ago. 2014. 
mídias sociais estão cada vez mais influenciando o desempenho das bibliotecas públicas. A pesquisa aponta que mais de $68 \%$ das bibliotecas públicas americanas fazem uso do Facebook para divulgação de seus serviços, eventos e atividades diárias.

Sobre as redes sociais Pontes e Santos (2011, p. 4) afirmam que "se constituem por um processo dinâmico de trocas de informações, elas contribuem para a interligação de indivíduos através da distribuição de informação e da comunicação [...]”. Esse processo, no contexto das bibliotecas públicas, promovem a interação entre a instituição, o usuário e a informação.

Para uma biblioteca pública estar presente em uma rede social como o Facebook contribui para uma maior visibilidade entre os usuários e para a rapidez da circulação da informação, como também, para uma resposta mais rápida dos serviços oferecidos. É, portanto, estar acompanhando a evolução dos tempos, das informações contidas nas tabulas de argila para os tablets modernos.

\section{Procedimentos metodológicos}

A investigação científica tem como propósito contribuir para a evolução do conhecimento humano. Trata-se do processo através do qual procura se dar respostas às indagações do problema. Bunge (1980, p. 19) afirma que investigação cientifica é "[...] é um procedimento regular, explícito e passível de ser repetido para conseguir-se alguma coisa, seja material ou conceitual". Para o encaminhamento dessa trilha metodológica é necessário um conjunto de "atividades sistemáticas e racionais que, com maior segurança e economia" (MARCONI; LAKATOS, 2010, p. 65) permita alcançar o objetivo da pesquisa, o método, que conduzirá o caminho investigativo.

Portanto, para o encaminhamento desta investigação usaremos dois métodos das ciências sociais: o fenomenológico e o funcionalista. Trivinos (1992) descreve a fenomenologia como o estudo das essências no mundo. Seu objetivo é chegar à essência dos fenômenos, descrever, compreender e interpretar esses fenômenos percebidos pelo homem. A fenomenologia surgiu na segunda metade do século XX a partir dos estudos sobre a intencionalidade da consciência humana de Franz Bretano. Neste estudo em particular, a fenomenologia irá contribuir para a compreensão do fenômeno das redes sociais para a circulação e disseminação da informação pelas bibliotecas públicas. 
O método funcionalista, que consiste em um método de interpretação (MARCONI; LAKATOS, 2010) irá auxiliar na compreensão dos componentes, relações e inter-relações sociais, uma vez em que "estuda a sociedade do ponto de vista da função de suas unidades, isto é, como sistema organizado de atividades" (MARCONI; LAKATOS, 2010, p. 92).

É um estudo exploratório que se caracteriza por conduzir a um estudo preliminar com o objetivo de compreender o fenômeno (GIL, 1999) e descritivo que tem por finalidade observar, registrar e analisar os fenômenos, sem interferência do investigador (GIL, 1999). Por fim, a abordagem da análise é caráter quali-quantitativo, por ter propriedades mensuráveis e ao mesmo tempo em que também tem propriedades subjetivas, portanto, a análise foi feita por combinação a fim de fortalecer os resultados da pesquisa a partir da triangulação das observações, perspectivas teóricas, fontes e metodologias (BRYMAN, 2005).

O corpus investigativo compreenderá as bibliotecas públicas no Estado do Ceará que estão integradas ao Sistema Estadual de Bibliotecas Públicas do Ceará (SEBP/CE).

\section{Resultados e Discussões}

A pesquisa foi realizada no período de novembro de 2012 e fevereiro de 2013 no próprio Facebook. As buscas compreenderam descritores como o nome completo da biblioteca pública, o nome da cidade, simplesmente 'biblioteca pública', 'biblioteca pública municipal' 'BPM' e outros. No Ceará, do total de 184 bibliotecas públicas municipais apenas 33 usam o Facebook para divulgar informações e serviços, o que corresponde a $18 \%$ e 151 ainda não usam esse recurso de comunicação, correspondendo a $82 \%$ do total, conforme podemos observar no Gráfico 1. 
Gráfico 1: Bibliotecas Públicas Municipais (BPM) do Ceará que utilizam Facebook

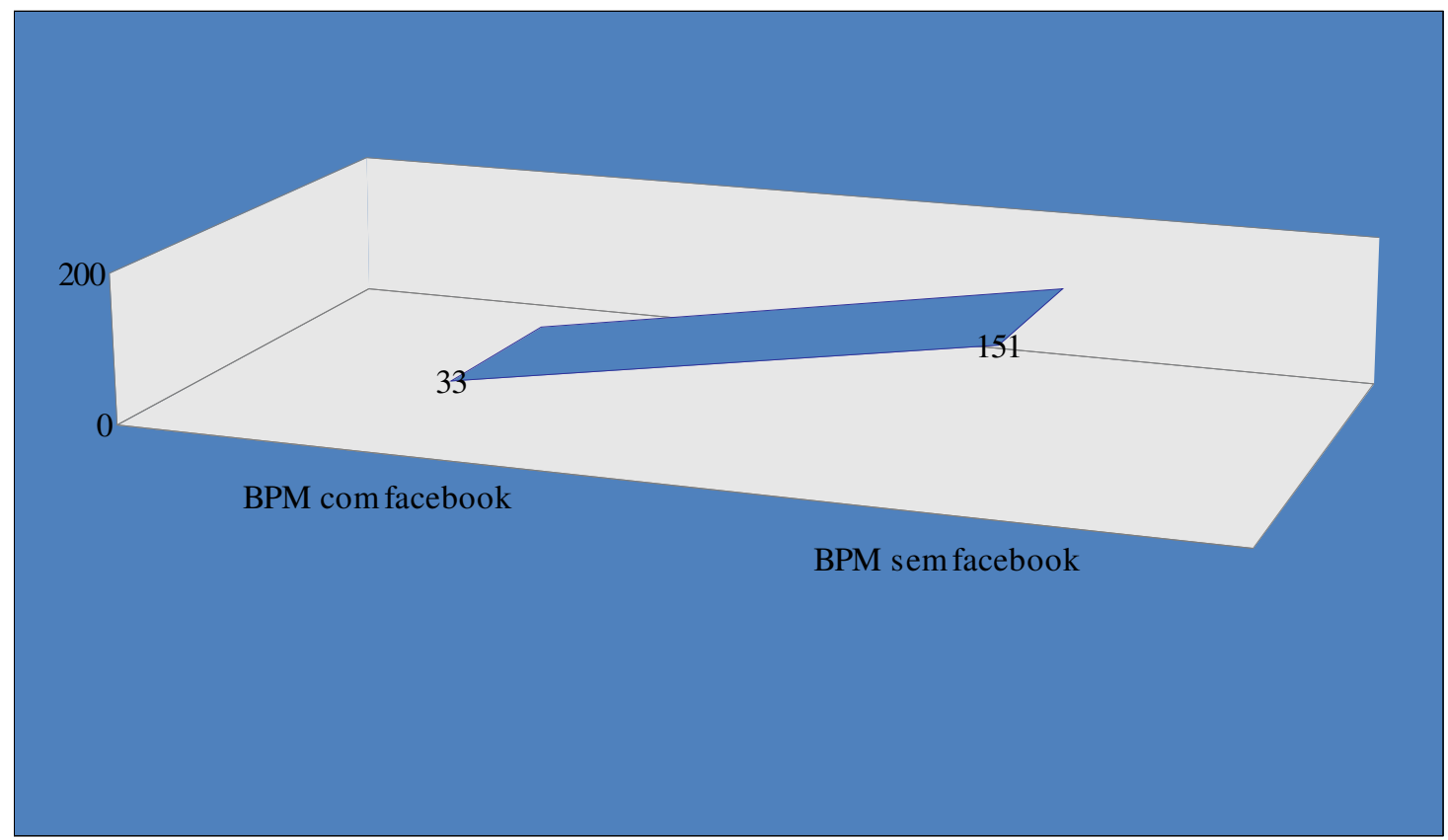

Fonte: Os Autores

Este é um resultado do pouco uso da internet nas bibliotecas públicas cearenses. Os gestores das bibliotecas ainda não atentaram para o indescritível alcance dessa ferramenta para uma divulgação maciça dos serviços oferecidos pela biblioteca. Outro fator é que a maioria dos municípios cearenses conta com ilhas digitais ou telecentros e apesar de alguns serem instalados dentro das próprias bibliotecas públicas, estes espaços acabam tratados como algo separado da biblioteca. Essas ilhas digitais ou telecentros poderiam ser incorporadas como serviços das próprias bibliotecas públicas e aproveitando o público presente para divulgar e dar maior visibilidade à bibliotecas e seus outros serviços.

No Gráfico 2 podemos observar o uso do Facebook pelas bibliotecas públicas por macrorregião administrativa, que aponta a macrorregião do Cariri e Centro Sul, a maior de todas com o maior percentual de bibliotecas públicas com Facebook, um total de 27\%, seguida pela macrorregião do Sertão Central com 24\%. Ao observarmos que as bibliotecas do Sertão Central totalizam a metade do número de bibliotecas do Cariri e Centro Sul, podemos afirmar que essa é a região que mais faz uso da rede social Facebook para divulgar seus serviços. 
Gráfico 2: Bibliotecas Públicas do Ceará com Facebook por Macrorregiões

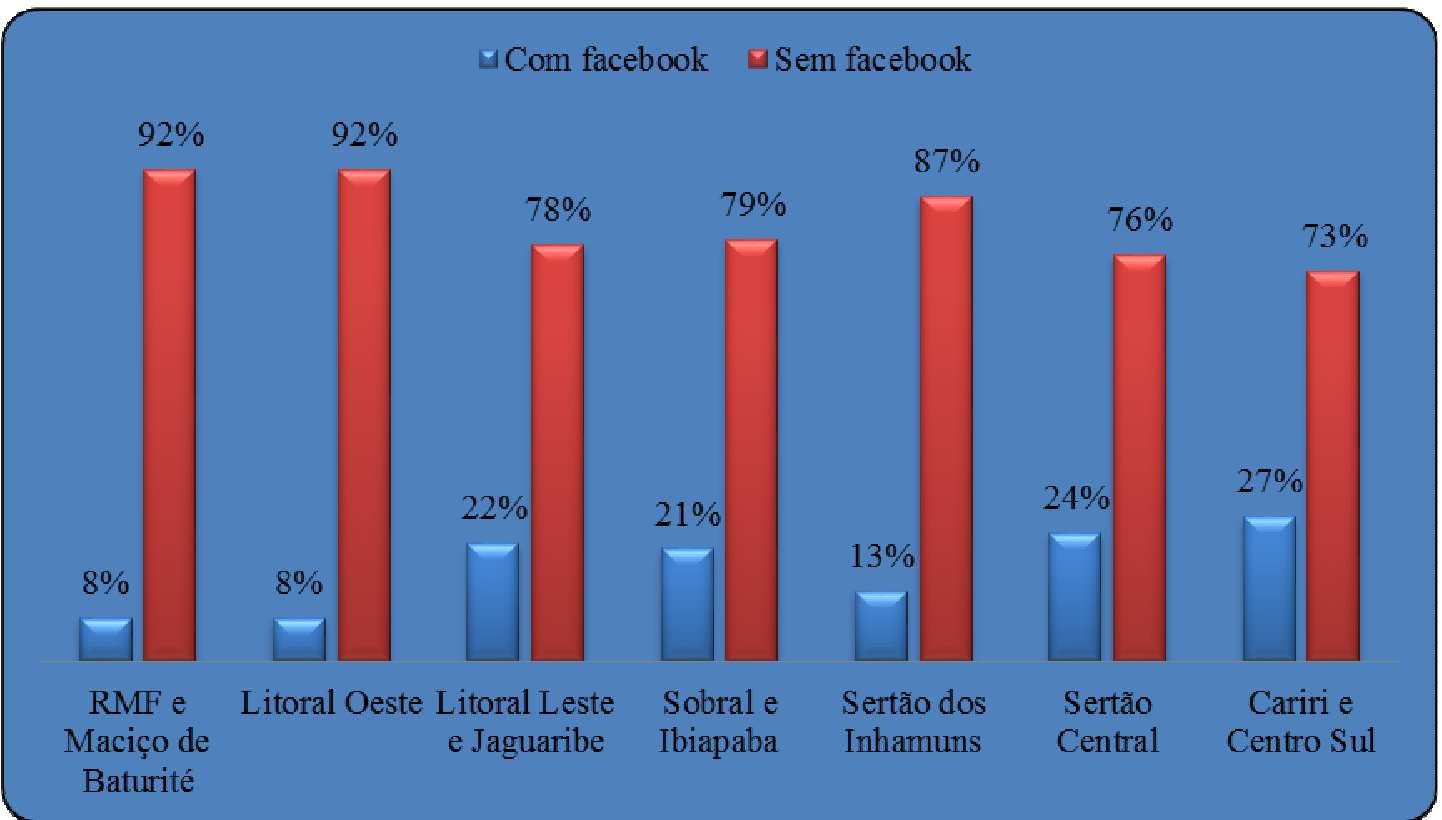

Fonte: Os Autores

Em seguida vem a macrorregião do Litoral Leste e Jaguaribe com $22 \%$ e a macrorregião de Sobral e Ibiapaba com 21\%, os Inhamuns com 13\% e a Região Metropolitana de Fortaleza e Maciço de Baturité e Litoral Oeste com $8 \%$ cada, como podemos observar no gráfico 2 .

Os dados apontam que as bibliotecas públicas cearenses fazem pouco uso da rede social Facebook para divulgação dos serviços e informações. Apesar do Brasil ocupar o $5^{\circ}$ lugar em conexão a internet, conforme dados do Ibope Média de $2012^{3}$ com 94,2 milhões de pessoas conectadas. Ainda segundo o Ibope de 2012 há uma contrastante desigualdade entre as regiões sul com $25,6 \%$ e sudeste com $26,6 \%$ e as regiões norte com $12 \%$ e nordeste com apenas $11,9 \%$ de pessoas com acesso à internet. As bibliotecas públicas poderiam suprir essa necessidade e minimizar a desigualdade social entre os internautas, sobretudo, se pensarmos na disponibilidade e acesso à informação como uma das funções da biblioteca pública, a sua função social, educativa e cultural.

O Centro de Estudo sobre as Tecnologias da Informação e da Comunicação (CETIC) do Brasil avaliou que o uso das redes sociais ocorre independentemente do nível socioeconômico. O CETIC realizou pesquisa e apontou que o uso das redes sociais pelas

\footnotetext{
${ }^{3}$ Disponível em: http://www.ibope.com.br/pt-br/noticias/paginas/acesso-a-internet-no-brasil-atinge-94-milhoesde-pessoas.aspx
}

InCID: R. Ci. Inf. e Doc., Ribeirão Preto, v. 5, n. 1, p. 112-123, mar./ago. 2014. 
classes A, B é de 73\%, C de 72\%, D e E de $69 \%^{4}$. Especificamente sobre o uso do Facebook a empresa de estatística sobre mídias sociais Socialbakers conclui que um terço da população brasileira tem um perfil. São 64,8 milhões de pessoas, correspondendo a um terço da população, o equivalente a $32,4 \%$, ficando atrás apenas dos Estados Unidos ${ }^{5}$.

Esses dados nos permitem compreender o fenômeno do uso das redes sociais pela sociedade e inferir que para as bibliotecas, sobretudo, as públicas, é uma excelente ferramenta para a circulação e disseminação da informação. Do universo de 184 bibliotecas públicas municipais, apenas 33 utilizam um perfil no Facebook para divulgar seus serviços, eventos e interagir com a comunidade usuária. Tomando como base a situação do Brasil quanto ao uso do Facebook atualmente, os dados de uso para as bibliotecas públicas cearenses, apresenta uma discrepância e contribui para que haja uma grande distância entre a biblioteca e os usuários.

Entretanto, não afirmamos que a lacuna existente entre o usuário e a biblioteca será suprida apenas com a criação do perfil da biblioteca pública na rede social. Porém, em um país em que um terço da população está conectada e ainda em consonância com as funções sociais da biblioteca pública, acreditamos que é o primeiro passo para alcançar o usuário.

\section{Considerações finais}

O presente artigo não objetivou aqui analisar ou avaliar a qualidade das informações obtidas por intermédio das redes sociais, mas, analisar o uso pelas bibliotecas públicas da rede social Facebook como canal para divulgação de serviços e informações.

Os dados apontaram para uso mínimo de $18 \%$ das bibliotecas publicas utilizando o Facebook como canal de informação. Esse uso mínimo das mídias sociais representa o pouco investimento das autoridades gestoras, que somada à falta de visão administrativa e conhecimento sobre tecnologias acabam por interferir na comunicação e disseminação de informações na biblioteca pública. Algumas bibliotecas localizadas no interior do Estado não têm sequer telefone para comunicação. Algumas infelizmente são pequenos depósitos de livros didáticos e literários que sem o devido tratamento e divulgação acumulam poeira nas estantes distribuídas pelo espaço físico.

\footnotetext{
${ }^{4}$ Disponível em: http://agenciabrasil.ebc.com.br/assunto-galeria/ceticbr

${ }^{5}$ Disponível em: http://www.socialbakers.com/blog/1290-10-fastest-growing-countries-on-facebook-in-2012
} 
A biblioteca pública não pode e nem deve ficar alheia aos avanços tecnológicos modernos, deve sim, usar toda e qualquer ferramenta para o engrandecimento da cultura e do conhecimento e para dar maior visibilidade à biblioteca pública.

\section{Referências}

ARAÚJO, Vânia Maria Rodrigues Hermes de. Estudo dos canais informais de comunicação técnica: seu papel na transferência de tecnologia e na inovação tecnológica. Ciência da Informação, Brasília, v. 8, n. 2, p. 79-99, 1979. Disponível em:

<http://revista.ibict.br/ciinf/index.php/ciinf/article/view/1530>. Acesso em: 19 set. 2012.

BRANDÃO, Oscar César; DUQUE, Cláudio Gottschalg. Comunicação científica contemporânea de vanguarda. In: DUQUE, Cláudio Gottschalg. (Org.). Ciência da informação: estudos e práticas. Brasília: Thesaurus, 2011.

BRYMAN, Alan. Quantity and quality in social research. New York: Routledge, 1995.

BUNGE, Mário. Epistemología. Barcelona: Siglo Veinteuno, 1980. Disponível em: $<$ http://librosuniversitarios.net/epistemologia-mario-bunge/>. Acesso em: 19 set. 2012.

CASTELLS, Manuel. A sociedade em rede. São Paulo: Paz e Terra, 1999. (A era da informação: economia, sociedade e cultura, v. 1)

DRUCKER, Peter. A quarta revolução da informação. Revista Exame, edição 669, 26 ago., 1998. Disponível em: <http://exame.abril.com.br/revista-exame/edicoes/0669/noticias/aquarta-revolucao-da-informacao-m0053768>. Acesso em: 19 set. 2012.

GIL, Antônio Carlos. Métodos e técnicas de pesquisa social. São Paulo: Atlas, 1999.

LENZI, Livia Aparecida Ferreira; BRAMBILA, Ednéa Zandonadi. Ciência da informação, ciência e revolução científica: breve histórico e reflexões. Informação e Informação,

Londrina, v. 11, n. 1, jan./jun., 2006. Disponível em:

$<$ http://www.uel.br/revistas/uel/index.php/informacao/article/view/1679/1430>. Acesso em: 19 set. 2012.

MARCONI Marina de Andrade; LAKATOS Eva Maria. Fundamentos de metodologia científica. 7. ed. São Paulo: Atlas 2010.

MARTELETO, Regina Maria. Informação, rede e redes sociais: fundamentos e transversalidades. Informação e Informação, Londrina, v. 12, n. especial, 2007. Disponível em: <http://www.uel.br/revistas/uel/index.php/informacao/article/view/1785>. Acesso em: 19 set. 2012.

OLIVEIRA, Marlene de. Canais formais de comunicação do conhecimento antropológico produzido no Brasil. 1989. 77f. Dissertação (Mestrado em Ciência da Informação) - 
Instituto Brasileiro de Informação em Ciência e Tecnologia, Universidade Federal do Rio de Janeiro, Escola de Comunicação, Rio de Janeiro, 1989.

PONTES, Euzébia Maria; SANTOS, Mônica Karina. O uso das redes sociais no âmbito das bibliotecas universitárias federais brasileiras. In: CONGRESSO BRASILEIRO DE BIBLIOTECONOMIA DOCUMENTAÇÃO E CIÊNCIA DA INFORMAÇAO, 24., 2011. Maceió. Anais eletrônicos... Maceió: FEBAB, 2011. Disponível em: $<$ http://febab.org.br/congressos/index.php/cbbd/xxiv/paper/view/370/403 > . Acesso em: 20 abr. 2013.

REGIS, Josiana Florêncio Viana; CAMPOS, Ana Célia Cavalcanti Fernandes. O paradigma tecnológico e a revolução informacional: fundamentos da sociedade da informação. In: CONGRESSO INTERNACIONAL EM SISTEMAS DE INFORMAÇAO E GESTAO DA TECNOLOGIA, 6., 2009. São Paulo. Anais eletrônicos... São Paulo: FEA/USP, 2009. Disponível em: <http://repositorio.ufrn.br:8080/jspui/handle/1/3136>. Acesso em: 19 set. 2012.

SANTOS, Paula Xavier dos. A dimensão política da disseminação da informação através do uso intensivo das tecnologias de informação e comunicação: uma alternativa à noção de impacto tecnológico. DataGramaZero, v. 5, n. 4, ago., 2004. Disponível em: $<$ http://www.dgz.org.br/ago04/Art_05.htm>. Acesso em: 19 set. 2012.

SANTOS, Plácida Leopoldina Ventura Amorim da Costa; CARVALHO, Ângela Maria Grossi de. Sociedade da informação: avanços e retrocessos no acesso e no uso da informação. Informação \& Sociedade, João Pessoa, v. 19, n. 1, p. 45-55, jan./abr. 2009. Disponível em: $<$ http://www.ies.ufpb.br/ojs2/index.php/ies/article/view/1782/2687>. Acesso em: 20 set. 2012.

TRIVINOS, Augusto Nibaldo Silva. Introdução à pesquisa em ciências sociais. São Paulo: Atlas, 1992. 